\title{
Effects of Water Soaked Height on the Deformation and Crushing Characteristics of Loose Gangue Backfill Material in Solid Backfill Coal Mining
}

\author{
Junmeng $\mathrm{Li}^{1,2}{ }^{\mathbb{D}}$, Yanli Huang ${ }^{1, *}$, Ming Qiao ${ }^{1}$, Zhongwei Chen ${ }^{2}$, Tianqi Song ${ }^{1}$, \\ Guoqiang Kong ${ }^{1}$, Huadong Gao ${ }^{1}$ and Lei Guo ${ }^{3}$ \\ 1 State Key Laboratory of Coal Resources and Safe Mining, School of Mines, China \\ University of Mining \& Technology, Xuzhou 221116, China; lijunmeng1201@163.com (J.L.); \\ tb16020013b1@cumt.edu.cn (M.Q.); stq344359844@163.com (T.S.); kgq9569913@163.com (G.K.); \\ gaohuadong1314@163.com (H.G.) \\ 2 School of Mechanical and Mining Engineering, the University of Queensland, St. Lucia, QLD 4072, Australia; \\ uqjli30@uq.edu.au \\ 3 College of Mining and Safety Engineering, Shandong University of Science and Technology, Qingdao 266590, \\ China; sdustgl@sdust.edu.cn \\ * Correspondence: 5306@cumt.edu.cn or huangyanli6567@163.com; Tel.: +86-139-0520-7498
}

Received: 23 April 2018; Accepted: 28 May 2018; Published: 30 May 2018

\begin{abstract}
In solid backfill coal mining (SBCM), loose gangue backfill material (LGBM) is used to backfill the goaf after coal resources are exploited from the underground mines. Under certain geological conditions, LGBM with a certain height may be soaked in the water, and then becomes saturated, significantly altering its mechanical properties. The confined compression experiments were used in this paper to analyze the deformation and the crushing characteristics of LGBM with varying water soaked heights in coal mines. The results showed that a large number of small holes that were distributed in the gangue blocks were the main reason why the material absorbed water and was softened. The crushing ratio and the maximum axial strain of LGBM samples gradually increased with the water soaked heights of the samples. In addition, there was a strong linear correlation between the crushing ratio and the maximum axial strain. When LGBM was used as a solid backfill material in SBCM, its deformation resistance would significantly decrease after it was soaked in the water. Higher water soaked height of LGBM led to lower deformation resistance and greater influence on the quality of backfilling. This research has great significance in getting a deep and better understanding of the mechanical properties of LGBM, as well as guiding engineering practice.
\end{abstract}

Keywords: solid backfill coal mining; goaf; water soaked height; loose gangue backfill material; deformation; crushing ratio

\section{Introduction}

Solid backfill coal mining (SBCM) is a green mining technology that can meet the challenges of gangue dumps on the surface and the coal mining under buildings, railways, and water bodies. This technology is aimed at using the solid waste material, such as loose gangue and fly ash, to backfill the goaf and to support the overburden strata after the coal resources are exploited from the underground. The main purpose is to stabilize the overlying strata and reduce surface subsidence in the process of recovering coal reserves that are located under buildings, railways, and water bodies, thus reducing piled gangue on the surface and the environmental pollution. Currently, this technology has become a preferable technological measure that is widely used in the modern green exploitation of coal resources [1,2]. In the process of SBCM, loose gangue backfill material (LGBM) and other 
solid backfill materials are transported by material-feeding shaft to the surge bin under the mine. When needed, these solid backfill materials are transported to the scraper conveyor suspended at the rear of the SBCM hydraulic support from the surge bin through an underground conveyor system. Then, these materials are offloaded from the discharge port with the flashboard at its bottom and filled into the goaf. After that, tamp mechanism, as a key structure in the backfilling process, pushes and compacts these materials to fully connect the immediate roof with required density and fully fill the goaf. Finally, these solid backfill materials become the main support bearing the overburden strata $[3,4]$. The basic principle of SBCM is shown in Figure 1.

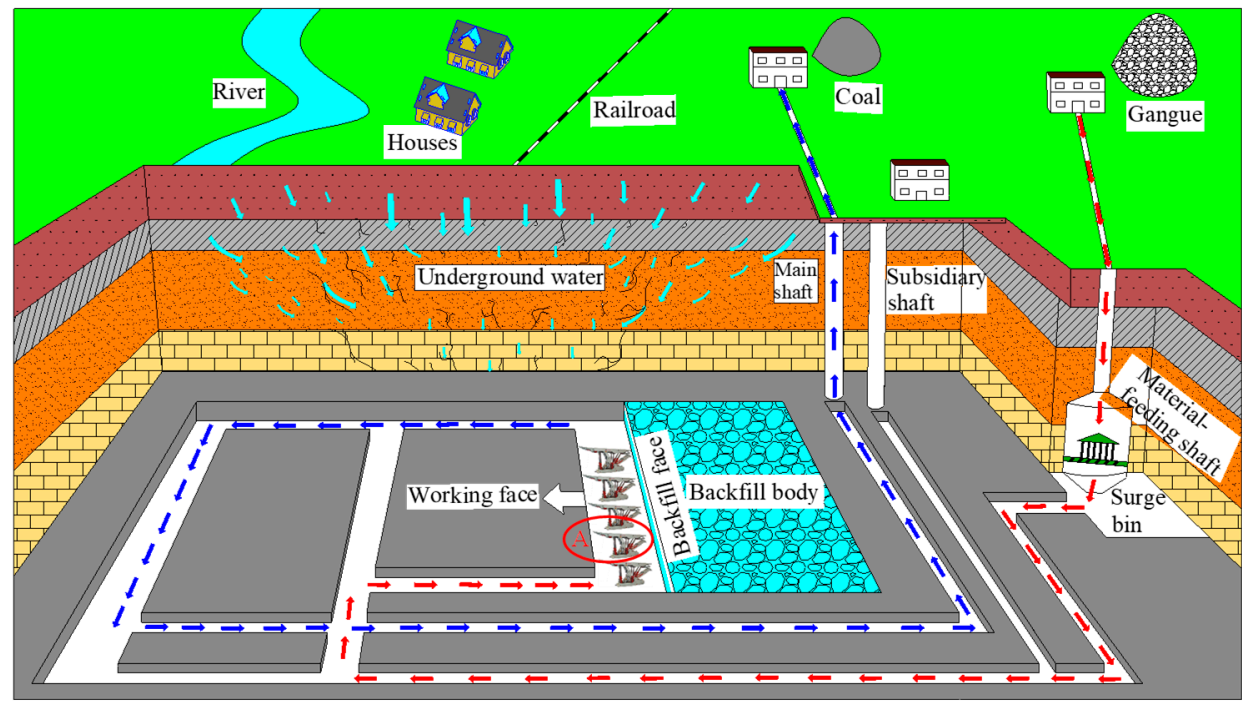

$\rightarrow$ The route of coal $\rightarrow$ The route of LGBM

Hydraulic supports for SBCM

(a)

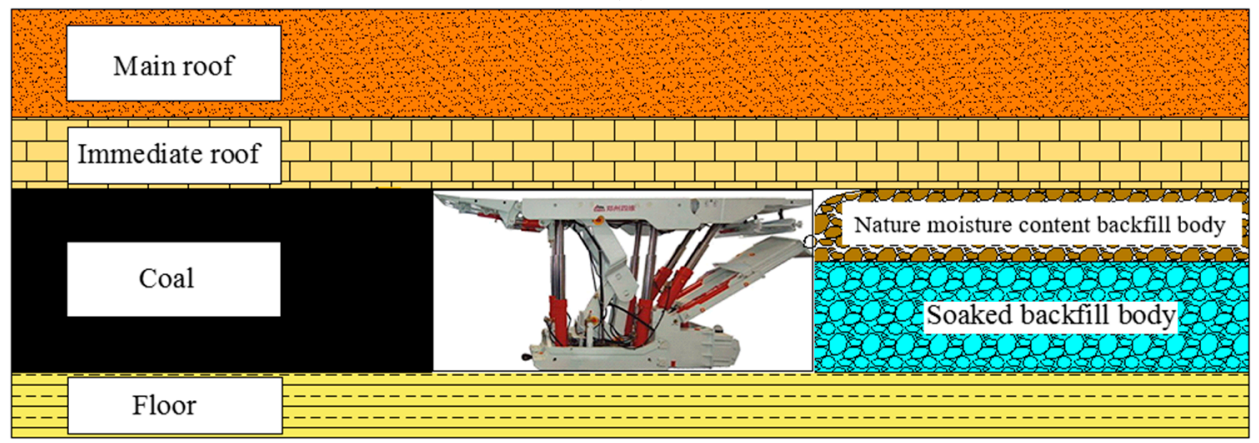

(b)

Figure 1. Basic principle of solid backfill coal mining (SBCM). (a) Overview; and, (b) Detailed view of hydraulic roof support at longwall/backfill face.

After the coal resources are exploited, water from the overburden layer seeps into the goaf through cracks and pores that exist in the roof. Wastewater that is produced in the process of coal production can also be stored in the goaf and soak in a portion of LGBM in the goaf. The amount of water in the goaf determines the soaked height of the LGBM, as is shown in Figure 1. The portion of the gangue that is soaked in water for a long time eventually becomes saturated, and its mechanical properties change dramatically. Thus, the mechanical strength of LGBM in bearing the overburden load varies with the water soaked height.

According to the research conducted by Yilmaz., and Fall., in terms of paste backfill, many factors affect its short-term and long-term strength and stability. They can be mainly classified into two categories: intrinsic factors and extrinsic factors. Intrinsic factors included all of the parameters that are 
related to the physical, chemical, and mineralogical properties of the three main components of paste backfill (the tailings, binder, and mixing water), as well as their mixing properties (e.g., water-to-cement ratio). Extrinsic factors are related to all phenomena that occurred in a stope filled with paste backfill and show interaction between the stope and the adjacent rock. Another extrinsic factor affecting the properties of cemented paste backfill is the in situ curing temperature [5]. In the process of SBCM, there were also many factors that would have influence on the filling quality, including the types and the mechanical properties of solid backfill materials, mining geological conditions, backfilling process design, etc. The mechanical properties of solid backfill materials are one of the most important factors determining the filling quality [3,4]. Water invariably presented in the goaf of coal mines. After the solid backfill, materials were soaked in the mine water and their mechanical properties would change significantly, which would affect the filling quality.

At present, a large number of researches on the mechanical properties of non-viscous bulk materials have been done. Marsal et al. [6-8] and Kong et al. [9] researched the crushing characteristic of rockfill materials. Their results showed that the crushing characteristic of particle is related to particle shape, strength, size, density, gradient, stress conditions, and other factors. Jaroslav [10] and Wang et al. [11] studied the stress and the strain of coarse grain materials, such as sand pebbles and rockfill, by using compression tests. They found that these materials clearly demonstrated their dilatancy effect. Bagherzadeh-Khalkhali [12] studied the effects of the maximum particle diameter on the shear strength of coarse soils. Kjaernsli et al. [13] and Hall et al. [14] carried out tri-axial compression tests on sand specimens and discovered that under fixed stress, irregular particles with rough surfaces are more easily to be crushed. In addition, well-graded sand specimens are less crushed than the poorly-graded sand specimens. Zhang et al. conducted the confined compaction tests on LGBM in the steel cylinder and obtained the relationships among strain, compaction, stress, as well as the influence of compaction time [15]. Huang et al. [16] used numerical simulations to study the macro-scale mechanical response and micro-scale movement characteristics of LGBM during tri-axial compression testing.

Clearly, there is an abundance of researches on non-viscous bulk materials with natural moisture content. However, very little researches have focused on the mechanical effects that are caused by soaking these materials in the water. After the solid backfill, materials are soaked in the mine water, and their mechanical properties will change dramatically, thus affecting the filling quality. As a result, the influence of water on the mechanical properties (the deformation and crushing characteristics) of LGBM will be studied in this paper. It is of great significance to guide the engineering practice of SBCM and to ensure the filling quality.

\section{Materials and Test Procedure}

\subsection{Materials and Sample Preparation}

The experimental study took SBCM face of Pingmei No. 12 mine (Henan province, China) as the project background. The goaf was backfilled with "excavation gangue" (gangue produced in the excavation process of rock roadway and coal roadway) piled on the surface, whose lithology is sandstone. The gangue was first crushed by a crusher and then filtered by a classifying screen to obtain five different distribution of particle sizes, including $10 \sim 20 \mathrm{~mm}, 20 \sim 30 \mathrm{~mm}, 30 \sim 40 \mathrm{~mm}, 40 \sim 50 \mathrm{~mm}$, and $50 \sim 60 \mathrm{~mm}$. When the samples were well prepared, the weight of gangue in each particle size group was $3.2 \mathrm{~kg}$, and the mass ratio was 1:1:1:1:1. Then, the LGBM samples were mixed evenly, and their distribution of particle size is listed in Table 1. After that, they were divided into two parts. The first part was kept at natural condition and the other was immerged in water for 48 days, until the gangues were fully saturated. 
Table 1. The particle size distributions of loose gangue backfill material (LGBM) samples.

\begin{tabular}{cccccc}
\hline Particle size $/ \mathrm{mm}$ & $10-20$ & $20-30$ & $30-40$ & $40-50$ & $50-60$ \\
\hline Content $/ \%$ & 20 & 20 & 20 & 20 & 20 \\
\hline
\end{tabular}

\subsection{Equipment}

A scanning electron microscope (SEM) was first used to analyse the density of the samples. In this experiment, FEI Quanta TM 250 SEM was adopted. Then, an X-ray diffractometer (D/Max-3B, Rigaku Company, Tokyo, Japan) was used to identify and to quantify the mineral and chemical contents of the samples. The equipment parameters were as follows: Incoming radiation mainly include copper target and $K \alpha$ radiation $(\lambda=1.5406 \AA)$, the $\mathrm{X}$-ray tube operating voltage was $35 \mathrm{kV}$, the tube current was $30 \mathrm{~mA}$, the slit width was $1^{\circ}$, and the scan rate was $8^{\circ} / \mathrm{min}$. Lastly, confined compression experiments were carried out to study the effects of water soaked height on the deformation and the crushing characteristics of LGBM. In the process of SBCM, when LGBM is filled into the goaf, it is surrounded by coal pillars, which limits the lateral displacement of LGBM, thus leading to LGBM only having vertical displacement, as is shown in Figure 1. As a consequence, the confined compression tests (the tri-axial compression was under uniaxial strain condition) are usually used to research the deformation characteristics of LGBM [17-20]. Before the experiment, LGBM was directly placed into the steel cylinder, as shown in Figure 2a. During the compression experiment, the lateral deformation of the sample was limited by the wall of the cylinder and the lateral stress was passively generated produced during the compression process due to Poisson's ratio effect. The actual lateral stress constantly changes with the change in vertical compression load.

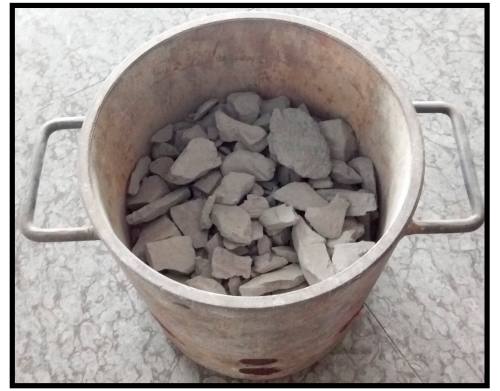

(a)

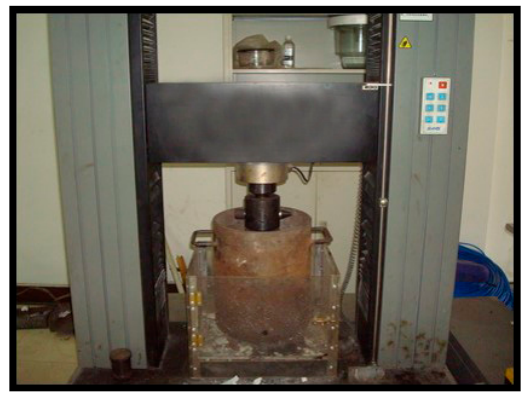

(b)

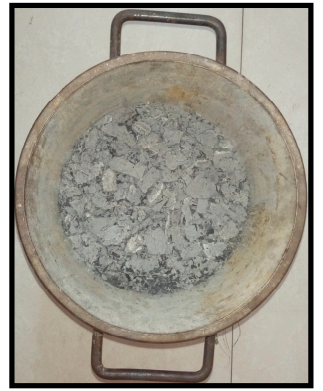

(c)

Figure 2. The process of confined compression tests. (a) Before experiment; (b) During confined compression experiment; and, (c) After experiment.

The loading control system that was used in the experiments was an MTS815 rock mechanics electrohydraulic servo test system (MTS company, Eden Prairie, MN, USA), as shown in Figure $2 b$. The container that was used in the confined compression tests of LGBM was a Q235 seamless steel drum that was specifically designed to test solid backfill materials that were used in coal mines. It had the following dimensions: the internal diameter is $350 \mathrm{~mm}$, the depth is $378 \mathrm{~mm}$, the loading platen thickness is $40 \mathrm{~mm}$, and the maximum loading height capacity is $338 \mathrm{~mm}$. The height of the material samples that were used in the following experiments was $338 \mathrm{~mm}$.

\subsection{Test Procedure}

Firstly, the mineral composition and mesostructure of the sandstone-type "excavation gangue" samples were tested by using the scanning electron microscope and X-ray diffractometer. Then, the MTS815 rock mechanics electrohydraulic servo system was applied to measure the basic mechanical properties of the rock samples. Finally, the confined compression tests were employed to examine the 
effects of water soaked height on the deformation and the crushing characteristics of LGBM. When designing the loading conditions, two key factors were taken into account: the mining depth and the interaction of LGBM with surrounding coal pillars. The maximum loading stress was used to represent the mining depth of $600 \mathrm{~m}$, and the uniaxial strain condition instead of conventional tri-axial condition, was applied for all of the tests in this work due to the restraint of its lateral movement from coal pillars. The same constant loading rate was applied for all of the tests and the loading rate was $1 \mathrm{kN} / \mathrm{s}$.

In the process of testing, the solid backfill materials with different water soaked heights in the mine were simulated by varying the water saturated height of the gangue. When the water soaked heights of LGBM are small, the mechanical properties of LGBM are less affected. Therefore, this study only considered the conditions that the water soaked height was higher than $50 \%$ of the total samples. At the same time, the LGBM with a water soaked height of 0 served as a control group. The saturated gangue was loaded into the bottom of the steel drum and the gangue with natural moisture content was placed on the top of the saturated. The test schemes included four-group experiments, as are listed in Table 2 and shown in Figure 3

Table 2. Test design.

\begin{tabular}{cc}
\hline Test Case & Saturated Gangue Content $($ Height Ratio) $/ \mathbf{h}=\mathbf{3 3 8} \mathbf{~ m m}$ \\
\hline$\# 1$ & $0 \mathrm{~h}$ \\
$\# 2$ & $0.5 \mathrm{~h}$ \\
$\# 3$ & $0.66 \mathrm{~h}$ \\
$\# 4$ & $1 \mathrm{~h}$ \\
\hline
\end{tabular}

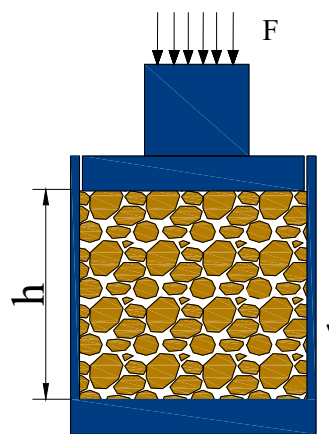

\#1 Case 1

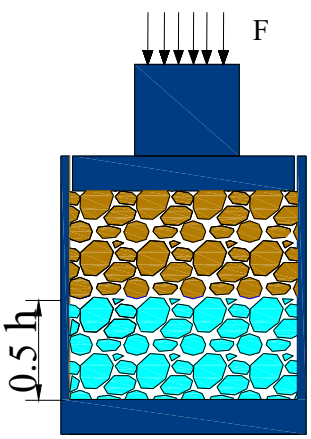

\#2 Case 2

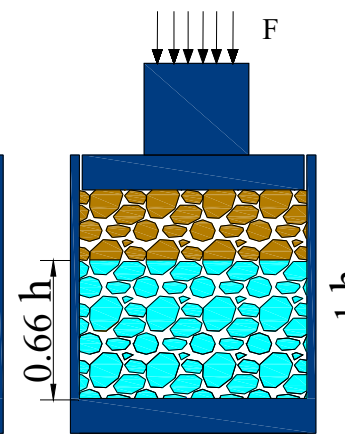

\#3 Case 3

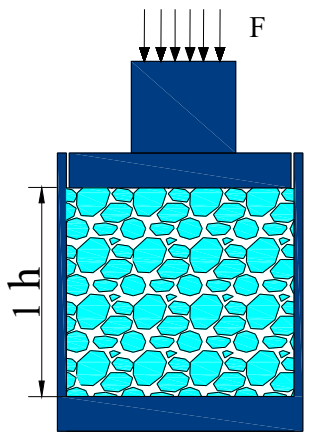

\#4 Case 4

Gangue with natural moisture content

Saturated gangue

Figure 3. The schematic diagrams of test schemes.

\section{Results and Analysis}

\subsection{Mineral Content and Mesostructure}

The mineral and chemical composition of the sandstone type "excavation gangue" samples were tested by using the X-ray diffracrometer. The X-ray diffraction spectrum of the samples is shown in Figure 4. The mineral and chemical composition of the samples are shown in Figures 5 and 6, respectively. 


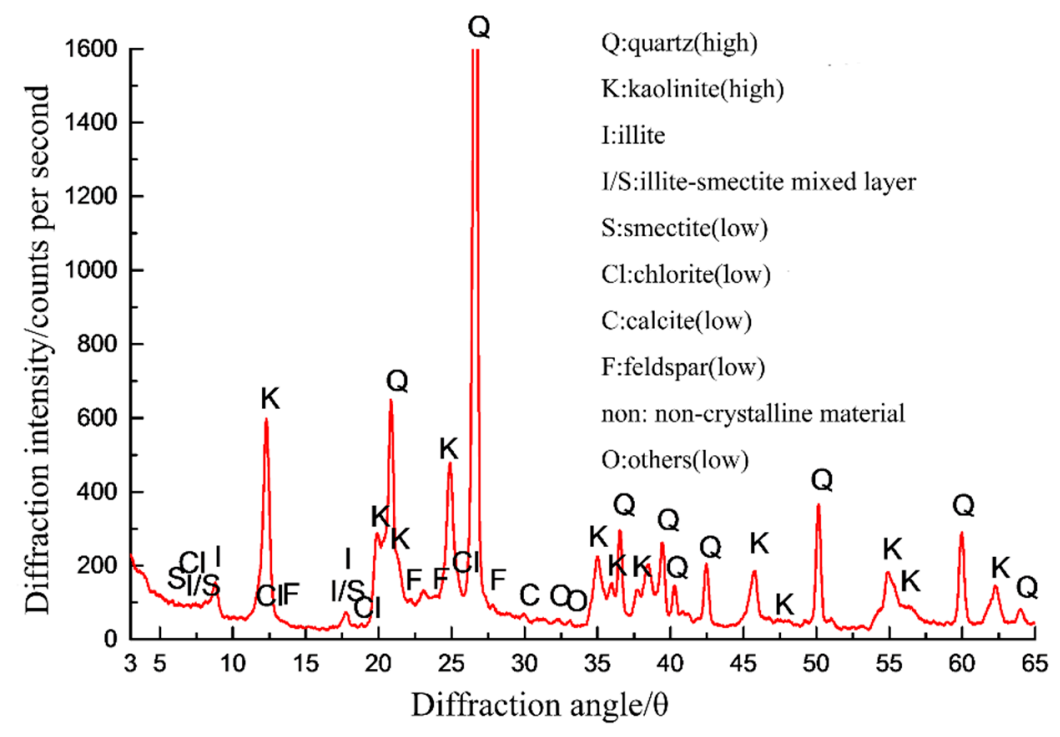

Figure 4. X-ray diffraction spectrum.

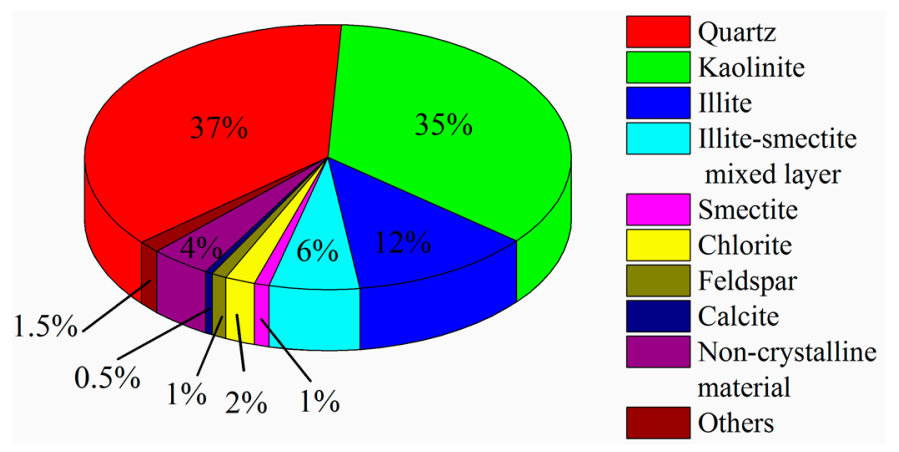

Figure 5. The mineral composition of the sandstone-type "excavation gangue" samples.

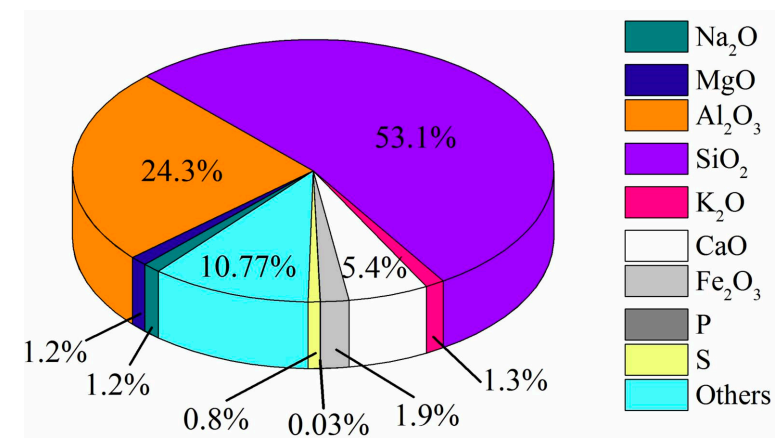

Figure 6. The chemical composition of the sandstone-type "excavation gangue" samples.

The study indicated that the mineral composition and the category of rocks are two main factors influencing the water absorption characteristics of rocks. The content of clay minerals, such as I/S (illite-smectite mixed layer), kaolinite, illite, and chlorite, is a key factor affecting water absorption characteristics of rocks. In particular, the montmorillonite has a stronger ability to absorb water [21]. Figures 4-6 show that the sandstone-type "excavation gangue" is composed mainly of $37 \%$ quartz, some illite, mixture of illite and smectite, as well as small amounts of chlorite. Therefore, the sandstone-type "excavation gangue" has a certain ability to absorb water. As for the chemical composition of the sandstone-type "excavation gangue" samples, the content of $\mathrm{SiO}_{2}$ is $53.1 \%$, which is 
relatively high, contributing to these samples having a rather high hardness and deformation resistance. In addition, the content of $\mathrm{Al}_{2} \mathrm{O}_{3}$ is $24.3 \%$, which makes these samples prone to hydrolysis when the samples are immersed in water.

SEM images of LGBM under different magnifications are shown in Figure 7.

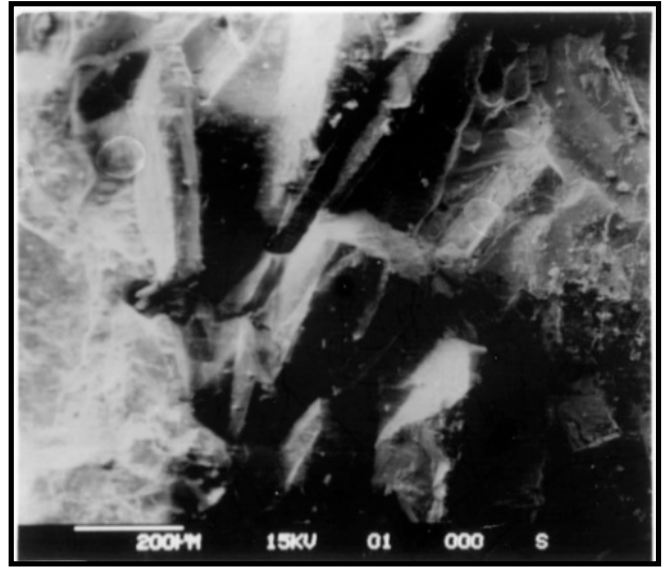

(a)

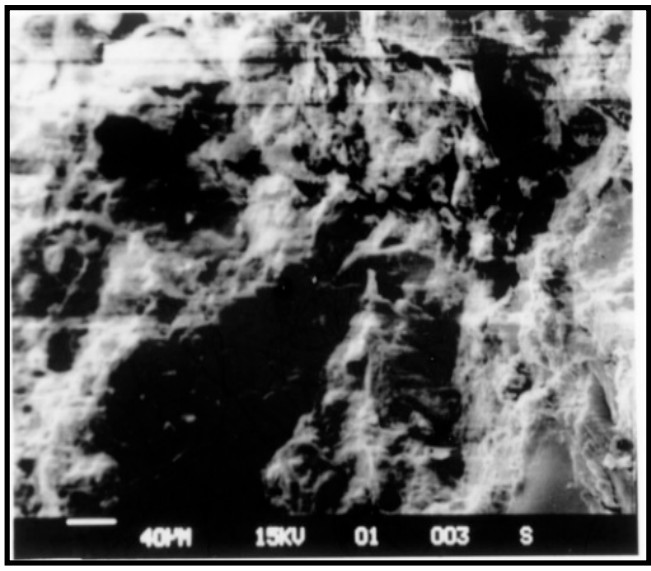

(c)

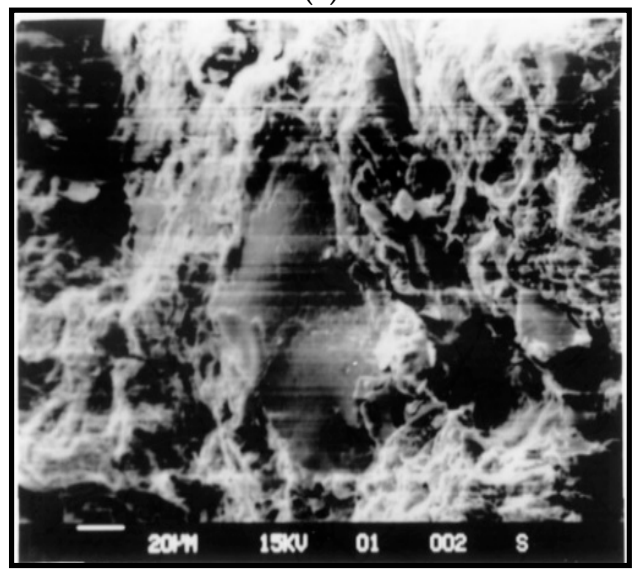

(e)

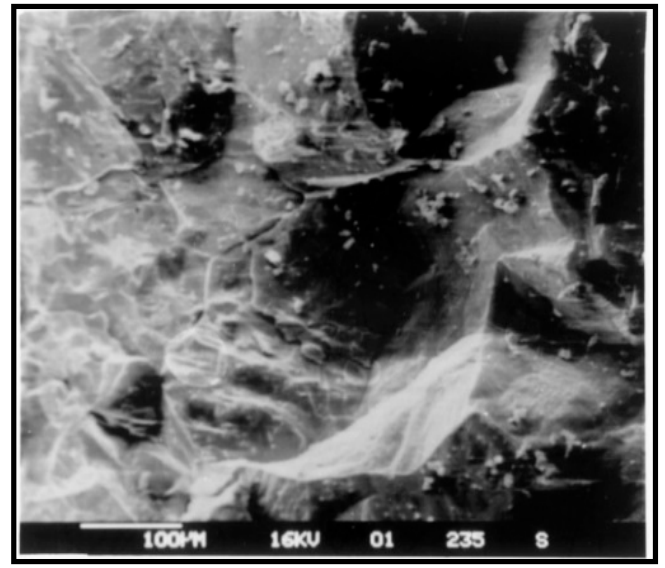

(b)

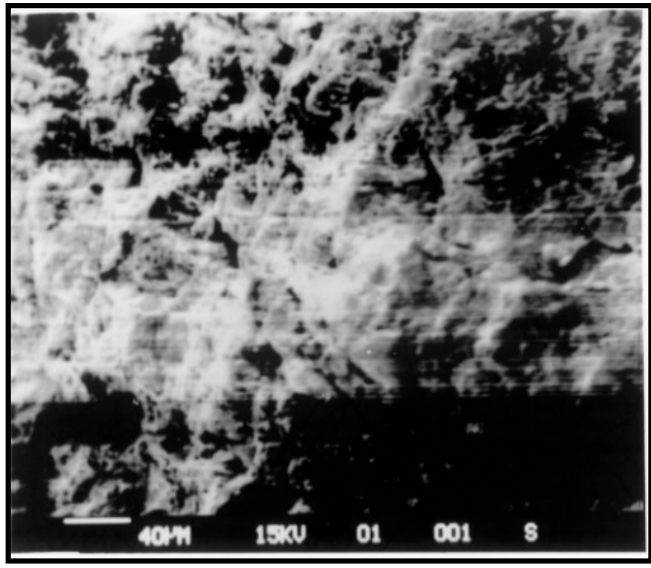

(d)

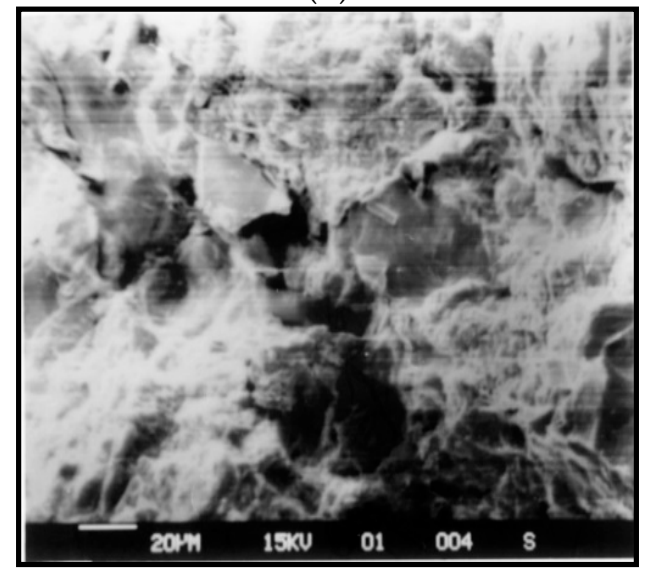

(f)

Figure 7. Scanning electron microscope (SEM) images of LGBM under various magnifications. (a) $80 \times$; (b) $160 \times$; (c) $200 \times$; (d) $250 \times$; (e) $350 \times$; and, (f) $450 \times$.

It is shown in Figure 7 that the coarse particles form a certain skeletal framework by being filled with smaller particles. The surface of particles is rough and irregular with a coarse texture. Many 
pores are visible. However, there are not many large holes or fissures. The existence of many small holes and crevices explains the reason why the material absorbs water and softens.

\subsection{Mechanical Properties of Gangue Block}

Basic mechanical parameters of the rocks, such as elastic modulus $E$ (secant modulus), Poisson's ratio $\mu$, uniaxial compressive strength $\sigma_{\mathrm{c}}$, uniaxial tensile strength $\sigma_{\mathrm{t}}$, cohesion $c$, and internal friction angle $\varphi$, were measured by uniaxial compression testing, point load splitting testing, and variable-angle shear testing under both saturated and natural-moisture-content conditions. In the experiments, a total of 42 samples were used and the details are listed in Table 3. Each experiment was repeated three times, and the average of the value of each mechanical parameter was taken as the ultimate value of each mechanical parameter. The ultimate results are listed in Table 4.

Table 3. The number of the samples.

\begin{tabular}{ccccccc}
\hline $\begin{array}{c}\text { Experiment } \\
\text { Name }\end{array}$ & \multicolumn{2}{c}{ Uniaxial Compression Testing } & Point Load Splitting Testing & \multicolumn{2}{c}{ Variable-Angle Shear Testing } \\
\hline Sample type & $\begin{array}{c}\text { Gangue with } \\
\text { natural moisture } \\
\text { content }\end{array}$ & $\begin{array}{c}\text { Saturated } \\
\text { gangue }\end{array}$ & $\begin{array}{c}\text { Gangue with } \\
\text { natural moisture } \\
\text { content }\end{array}$ & $\begin{array}{c}\text { Saturated } \\
\text { gangue }\end{array}$ & $\begin{array}{c}\text { Gangue with } \\
\text { natural moisture } \\
\text { content }\end{array}$ & $\begin{array}{c}\text { Saturated } \\
\text { gangue }\end{array}$ \\
\hline Number & 3 & 3 & 3 & 3 & 15 & 15 \\
\hline
\end{tabular}

Table 4. Basic mechanical properties.

\begin{tabular}{ccccccc}
\hline Sample Type & $\boldsymbol{E} / \mathrm{GPa}$ & $\mu$ & $\sigma_{\mathrm{c}} / \mathbf{M P a}$ & $\sigma_{\mathrm{t}} / \mathbf{M P a}$ & $\boldsymbol{c} / \mathbf{M P a}$ & $\boldsymbol{\varphi}^{\circ}$ \\
\hline Gangue with natural moisture content & 74.58 & 0.18 & 134.33 & 18.85 & 12.91 & 37.65 \\
Saturated gangue & 65.21 & 0.16 & 121.14 & 16.56 & 10.23 & 35.12 \\
\hline
\end{tabular}

\section{(1) Uniaxial compression testing}

The sample was placed on MTS815 rock mechanics electrohydraulic servo test system and was compressed at the rate of $500 \mathrm{~N} / \mathrm{s}$, and the pressure was recorded. In this experiment, four axial strain gauges were employed to measure the axial strain and the lateral strain of the samples. Specifically, two strain gauges were used to monitor the axial strain, and the other two strain gauges were used to monitor the lateral strain. The layout of the strain gauges is shown in Figure 8. The tests were repeated three times, and the average of the axial strain values and lateral strain values that were obtained through three tests were taken as the ultimate result.

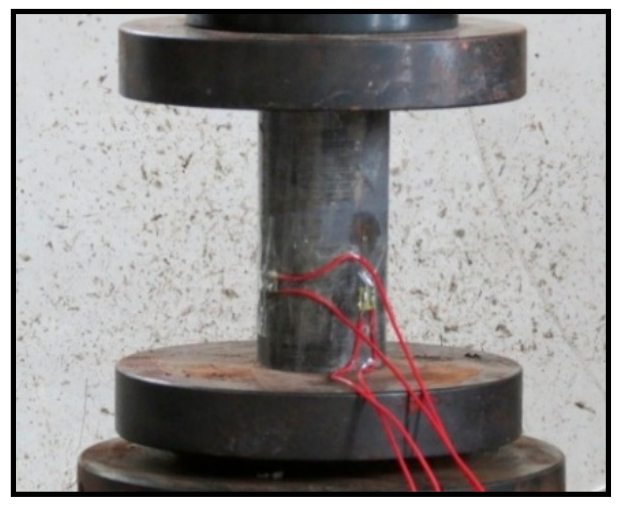

Figure 8. Uniaxial compression testing of gangue block. 
(2) Point load splitting testing

The sample was placed on the point splitting clamp and split at the rate of $500 \mathrm{~N} / \mathrm{s}$, during which time the peak pressure was recorded. The tests were repeated three times, and the average of peak pressure obtained through three tests was taken as the ultimate result. The experimental process is shown in Figure 9.

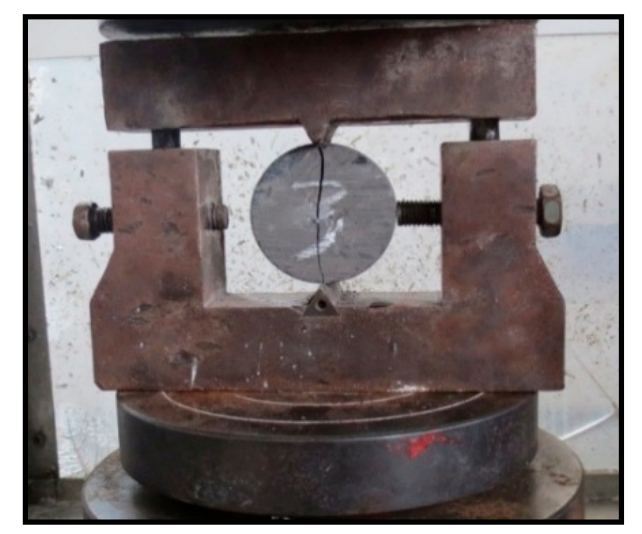

Figure 9. Point load splitting testing of gangue block.

(3) Variable-angle shear testing

In the experiment, the shear angles were respectively taken $45^{\circ}, 50^{\circ}, 55^{\circ}, 60^{\circ}$, and $65^{\circ}$. The samples were loaded to damage at the rate of $500 \mathrm{~N} / \mathrm{s}$, and the peak pressure was recorded. The experimental process is shown in Figure 10.

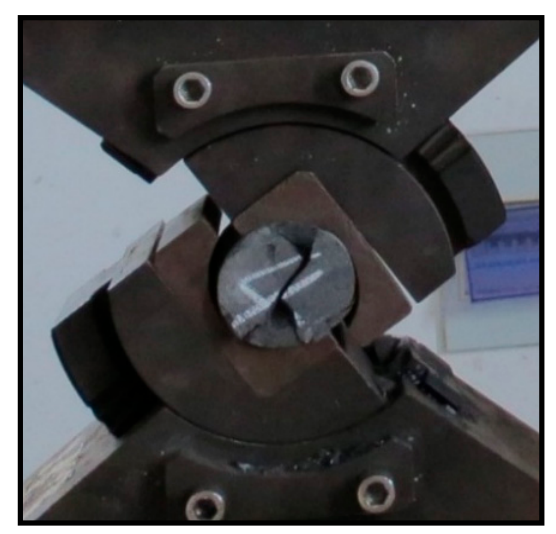

Figure 10. Variable-angle shear testing of gangue block.

Table 4 shows that the basic mechanical properties of the sandstone-type "excavation gangue" decreased after the gangue was soaked in the water and became saturated. To be specific, gangue's elastic modulus $E$, uniaxial compressive strength $\sigma_{\mathrm{c}}$, and uniaxial tensile strength $\sigma_{\mathrm{t}}$, respectively, decreased from $74.58 \mathrm{GPa}, 134.33 \mathrm{MPa}$, and 18.85 $\mathrm{MPa}$ under a natural-moisture-content condition to 65.21 GPa, 121.14 MPa, and 16.56 MPa under a saturated condition. In addition, its cohesion $c$ dropped from 12.91 MPa under a natural-moisture-content condition to $10.23 \mathrm{MPa}$ under a saturated condition, reducing by $20.8 \%$. Similarly, its friction angle $\varphi$ decreased from $37.65^{\circ}$ to $35.12^{\circ}$, reducing by $6.7 \%$. This means that the hardness of the gangue decreased significantly after the gangue was soaked to saturation, and the gangue was more easily damaged when compressed. 


\subsection{Deformation Characteristics of LGBM}

Figure 11 shows the axial strain-stress curves of the samples in each test case of the confined compression testing. Field monitoring datas from a number of mines (e.g., Pingdingshan twelfth coal mine [22], Zhai zhen coal mine [23], and Jining 3\# coal mine [24]) have consistently shown that after LGBM is backfilled into the goaf, the roof experiences rapid subsidence (i.e., sagging), with a sagging rate of greater than $0.075 \mathrm{~m} /$ month (average value of the three Coal Mines). It is believed the subsidence reflects the compaction of the solid backfill materials are also in a rapid deformation stage with the same rate. When the roof sagging rate drops to less than $0.0075 \mathrm{~m} / \mathrm{month}$ (average value of the three Coal Mines), the overburden strata is considered to be at a stable subsidence stage, so is the solid backfill materials. For this reason, in this work, the two key values 0.075 and 0.0075 were selected to divide the axial strain-axial stress curve of LGBM into three segments (rapid deformation stage, slow deformation stage, and stable deformation stage). The sagging rate was the slope of strain-stress curve, which was defined as the ratio of strain change due to stress change for each stress step. The maximum applied pressure in these tests was $16 \mathrm{MPa}$. When the load reached $16 \mathrm{MPa}$, the corresponding axial strain of the samples at that time was defined as the maximum axial strain. The relationship between the maximum axial strain and the height ratio of saturated gangue in the sample is shown in Figure 12.

Figures 11 and 12 show that as the load increased, the overall deformation of the samples in each test case could be divided into three segments: rapid deformation (segment I), slow deformation (segment II), and stable deformation (segment III). All of the samples were in the slow deformation stage when the applied axial stress was around 1.7 MPa. When the applied axial stress was around $12 \mathrm{MPa}$, the samples were in the stable deformation stage. At a given level of axial stress, the axial strain increased with the height ratio of saturated gangue in the sample. This is because the hardness of the gangue decreases after gangue is soaked in water. Gangue particles are more easily to be crushed under the compressive loading after the materials are saturated, which makes the saturated portion of the samples deformed more easily in the compression testing.

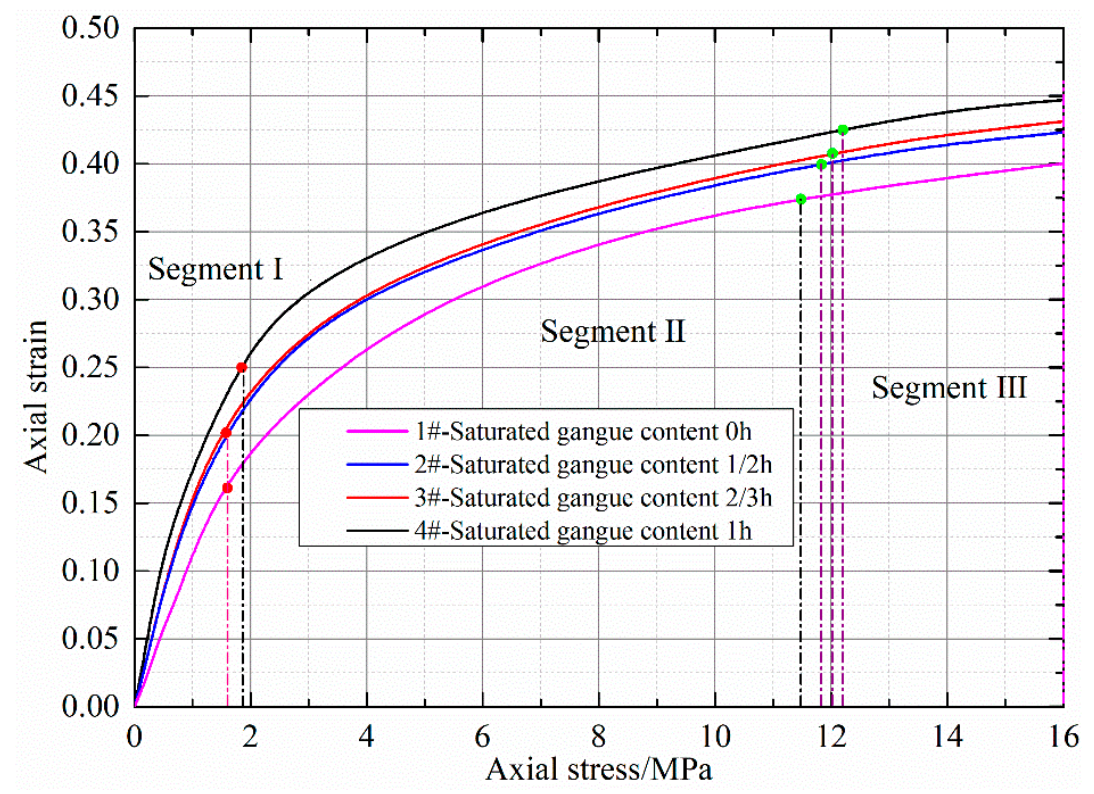

Figure 11. Axial strain-axial stress $(\varepsilon-\sigma)$ curves. 


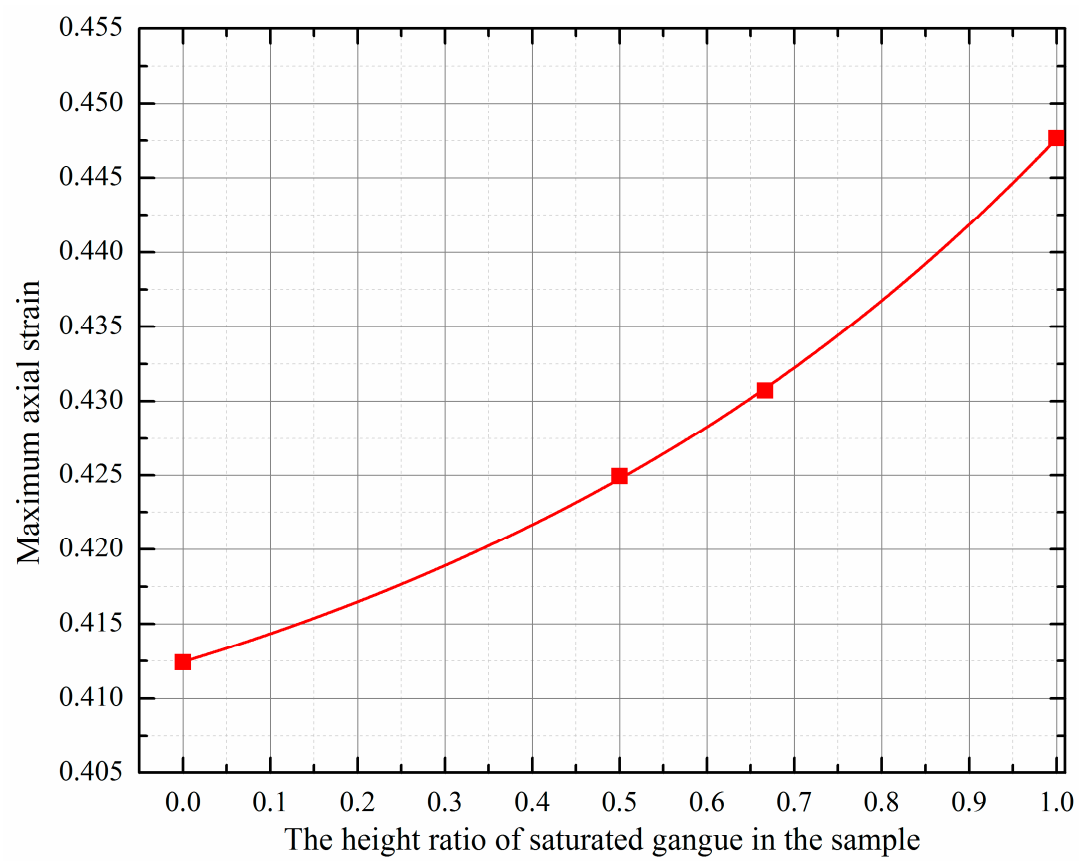

Figure 12. The relationship between the maximum axial strain and the height ratio of saturated gangue in the sample.

Therefore, the height ratio of saturated gangue in the samples was higher, the overall axial strain of the samples was greater. When the samples \#1-\#4 reached the slow deformation stage, their axial strain was $0.161,0.2,0.2$, and 0.25 , respectively. When the samples reached the stable deformation stage, the axial strain was $0.374,0.398,0.408$, and 0.425 , respectively. There was an exponential relationship between the maximum axial strain and the height ratio of saturated gangue in the sample. The maximum axial strain of the samples \#1-\#4 were $0.412,0.425,0.431$, and 0.448 , respectively. When compared with the maximum axial strain of sample \#1, the maximum axial strain of samples \#2-\#4 increased by $3.2 \%, 4.6 \%$, and $8.7 \%$, respectively. Apparently, these changes were significant.

The above results indicated that the deformation resistance of LGBM used in SBCM would become significantly lower after it was soaked in water underground the mine. The higher the water level of LGBM, the lower the deformation resistance of the materials, leading to larger influence on the quality of backfill.

\subsection{Crushing Characteristic of LGBM}

(1) Quantitative index of particle crushing

In the loading process of gangue, the grain will be crushed. In order to study the impact of grain crushing on the strength and the deformation characteristics of LGBM, there is a need to quantitatively reflect the crushing degree of particle. Currently, the Marsal crushing ratio $\left(B_{\mathrm{g}}\right)$ [6], particle size control difference $(B)$ [25], and relative crushing ratio $\left(B_{\mathrm{r}}\right)$ [26] are considered as three different quantitative indexes that are the most commonly used in geotechnical engineering. The Marsal crushing ratio $\left(B_{g}\right)$ is defined as the sum of positive values of difference in particle content with different gradation before and after the test, which is expressed as a percentage. Its computational formula is, as follows:

$$
B_{\mathrm{g}}=\sum W_{\mathrm{ki}}-W_{\mathrm{kf}}
$$

where, $W_{\mathrm{ki}}$-particle content of a certain gradation in size before the test; and, $W_{\mathrm{kf}}$-the corresponding particle content of the identical gradation in size after the test. 
The Marsal crushing ratio is a multi-gradation difference-value summation method, which can reflect the full aspect of crushing condition of particle. Having the merits of simple calculation and clear physical definition, as well as high accuracy, which can meet the need of practical engineering, the Marsal crushing ratio $\left(B_{g}\right)$ was used in this study as an essential quantitative index to describe the crushing condition of particle.

(2) Quantitative analysis of loose gangue crushing

After testing, the samples were allowed to dry naturally. Then, they were sieved to obtain the proportions of each particle size group and crushing ratio listed in Table 5. Figure 13 shows the relationship between the maximum axial strain and saturated gangue content, as well as the relationship between the crushing ratio and the saturated gangue content. Figure 14 shows the relationship between the maximum axial strain and the crushing ratio of each sample.

Table 5. Percentage of each particle size group and crushing ratio for each sample after testing.

\begin{tabular}{ccccccccc}
\hline \multicolumn{7}{c}{ Percentage of Each Particle Size Group/\% } \\
\hline \multirow{2}{*}{ Range of Particle Diameters } & $\begin{array}{c}\mathbf{0 - 1 0} \\
\mathbf{m m}\end{array}$ & $\begin{array}{c}\mathbf{1 0 - 2 0} \\
\mathbf{m m}\end{array}$ & $\begin{array}{c}\mathbf{2 0 - 3 0} \\
\mathbf{m m}\end{array}$ & $\begin{array}{c}\mathbf{3 0 - 4 0} \\
\mathbf{m m}\end{array}$ & $\begin{array}{c}\mathbf{4 0 - 5 0} \\
\mathbf{m m}\end{array}$ & $\begin{array}{c}\mathbf{5 0 - 6 0} \\
\mathbf{m m}\end{array}$ & $\begin{array}{c}\text { Crushing } \\
\text { Ratio } \boldsymbol{B}_{\mathbf{g}} / \mathbf{\%}\end{array}$ \\
\hline \multirow{4}{*}{ Sample name } & Before testing & 0 & 20.00 & 20.00 & 20.00 & 20.00 & 20.00 & 0 \\
& $\# 1$ & 43.11 & 21.43 & 13.28 & 9.39 & 10.79 & 1.98 & 44.56 \\
& $\# 2$ & 47.50 & 20.68 & 12.66 & 8.53 & 8.02 & 2.32 & 48.47 \\
& $\# 3$ & 48.70 & 20.62 & 12.90 & 10.22 & 4.95 & 2.65 & 49.28 \\
& $\# 4$ & 48.41 & 18.67 & 13.50 & 9.38 & 10.04 & 0 & 58.41 \\
\hline
\end{tabular}

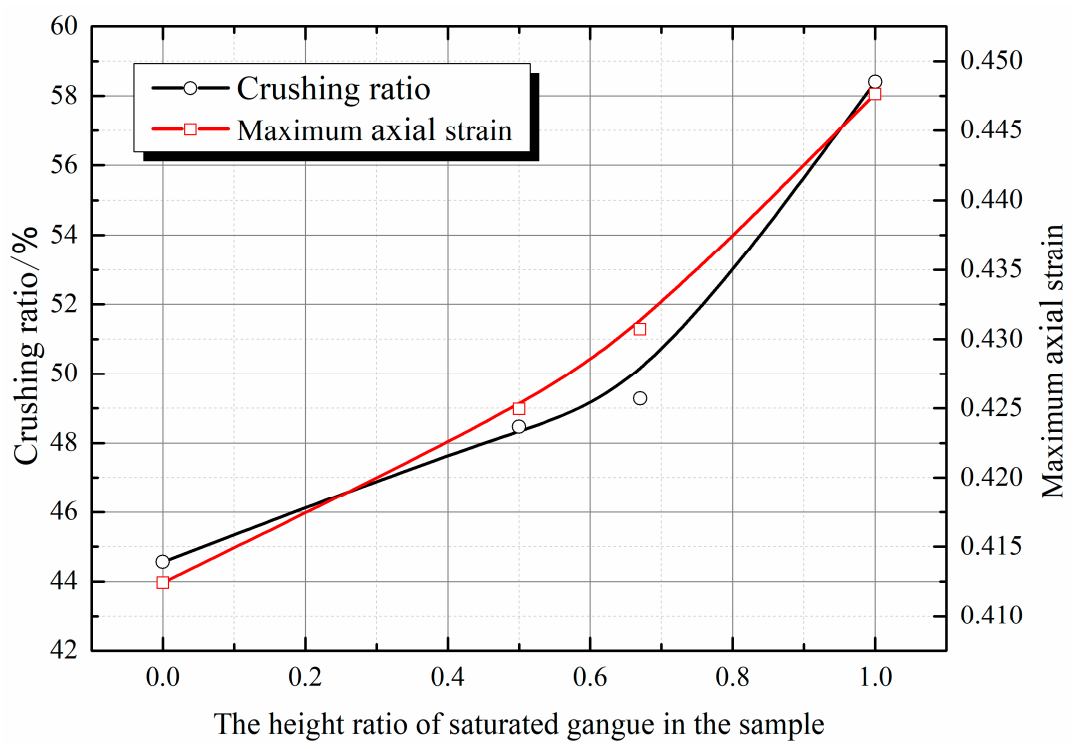

Figure 13. The relationship of the saturated gangue content with the crushing ratio or the maximum axial strain.

It can be obtained from Table 5 and Figures 13 and 14 that when the load reached $16 \mathrm{MPa}$, the particles of all loose gangue samples would be crushed significantly. The crushing ratios were all higher than $40 \%$. The crushing ratio increased with the height ratio of saturated gangue in the sample. As for the samples that were not saturated in the water, the crushing ratio was $44.56 \%$. In terms of the samples with the height ratio of saturated gangue of $0.5 \mathrm{~h}, 0.66 \mathrm{~h}$, and $1 \mathrm{~h}$, the crushing ratios were $48.47 \%, 49.28 \%$, and $58.41 \%$, respectively, rising by $8.8 \%, 10.6 \%$, and $31.1 \%$, respectively, when compared with the crushing ratio of the samples that were not saturated in the water. This can be explained by significantly decreased hardness of the saturated samples. When the samples were 
compressed under the same maximum axial stress of $16 \mathrm{MPa}$, the higher the height ratio of saturated gangue in the sample, the higher the crushing ratio and axial strain. In addition, there is a strong linear relationship between the axial strain and the crushing ratio, meaning that in the process of compression, particle crushing is the main cause of the deformation of the samples.

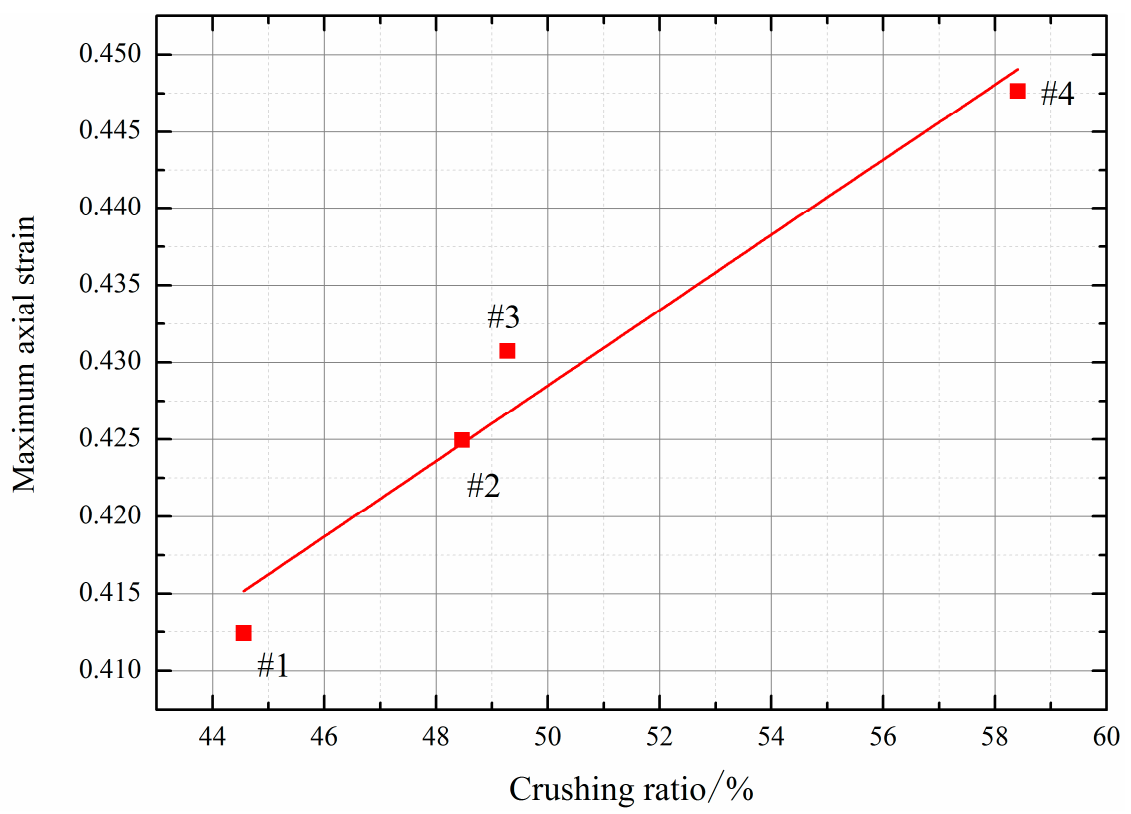

Figure 14. The relationship between the maximum axial strain and the crushing ratio.

\section{Conclusions}

This paper describes the experiments that were conducted to examine the mineral composition, mesostructure, and basic mechanical parameters of gangue rock. Then, details of the confined compression experiments that were carried out to study the effects of water soaked height on the deformation and the crushing characteristics of LGBM are presented. The conclusions are as follows:

(1) Sandstone-type "excavation gangue" is mainly composed of two minerals: quartz and kaolinite, with quartz and kaolinite accounting for 37\% and 35\% of the whole content, respectively. There are many small holes in the gangue material, which are the main reason why the material absorbs water and softens.

(2) The hardness of sandstone-type "excavation gangue" decreases significantly after the gangue is soaked in water. At a given load, the particles of saturated gangue are more easily crushed than gangue with natural moisture content.

(3) Under a given level of applied axial stress, the axial strain of gangue samples increased with the height ratio of saturated gangue in the sample. There was an exponential relationship between the maximum axial strain and the height ratio of saturated gangue in the sample. It had been shown that LGBM that is used to backfill the goaf in SBCM loses a certain amount of its ability to resist deformation after it is soaked in water existing in the mine. The higher the water level of the solid backfill materials was, the less likely that the solid backfill material can resist deformation, leading to a greater impact on the quality of backfill.

(4) When the loose gangue samples were compressed at $16 \mathrm{MPa}$, a higher saturated height ratio of the samples corresponded to a larger crushing ratio. The crushing ratios were all higher than $40 \%$. In addition, the maximum axial strain was strongly correlated to the crushing ratio, meaning that particle crushing was the main cause of deformation of the gangue samples in the compression process. 
There are some limitations in this study. Besides LGBM, the solid backfilling materials also include loess, aeolian sand, fly ash, and so on. This work solely focusses on the LGBM material and only single LGBM particle size distribution feature was studied. In the future studies, the effects of water soaked height on the deformation and the crushing characteristics of different solid backfilling materials would be strongly recommended. Moreover, the maximum pressure that was applied in this work was $16 \mathrm{MPa}$, which may not be representative of coal mining conditions at greater depth, thus it is recommended that the deformation characteristics of LGBM under greater loading conditions be studied in the future. In this work, the lateral deformation was monitored via two strain gauges, the average value was used together with the vertical displacement measurements to determinate the Poisson's ratio. The value may not be very reliable due to the limitation of the points, but this does not sacrifice the aim of the measurement, which is to gain the information of the key mechanical properties of gangue and how they are different to other rocks.

Author Contributions: J.L. and Y.H. conceived and designed the experiments; T.S. and G.K. performed the experiments; M.Q. and H.G. analyzed the data; L.G. contributed materials; J.L. wrote the paper; Y.H. and Z.C. modified the paper.

Acknowledgments: Financial support for this work provided by the Fundamental Research Funds for the Central Universities (2017BSCXA20) and Postgraduate Research \& Practice Innovation Program of Jiangsu Province (KYCX17_1552) are gratefully acknowledged.

Conflicts of Interest: The authors declare no conflicts of interest.

\section{References}

1. Miao, X.; Zhang, J.; Guo, G. Waste Backfilling Method and Technology in Fully Mechanized Coal Mining; China University of Mining \& Technology press: Xuzhou, China, 2010.

2. Miao, X. Progress of fully mechanized mining with solid backfilling technology. J. China Coal Soc. 2012, 37, 1247-1255.

3. Zhang, Q.; Zhang, J.X.; Ju, F.; Tai, Y.; Li, M. Theoretical research on mass ratio in solid backfill coal mining. Environ. Earth Sci. 2016, 75, 586. [CrossRef]

4. Li, M.; Zhang, J.; Huang, Y.; Zhou, N. Effects of particle size of crushed gangue backfill materials on surface subsidence and its application under buildings. Environ. Earth Sci. 2017, 76, 603. [CrossRef]

5. Yilmaz, E.; Fall, M. Paste Tailings Management, 1st ed.; Springer International Publishing: Cham, Switzerland, 2017.

6. Marsal, R.J. Mechanical Properties of Rockfill Embankment Dam Engineering; John Wiley and Sons Inc.: New York, NY, USA, 1973; pp. 109-200.

7. Marsal, R.J. Large scale testing of rockfill materials. J. Soil Mech. Found. Div. 1967, 93, 27-43.

8. Marsal, R.J. Earth-Rock Dam Project; Hydraulic press: Jiangsu, China, 1979.

9. Kong, D.; Zhang, B.; Sun, X. Triaxial Tests on Particle Breakage Strain of Artificial Rock Fill Materials. Chin. J. Geotech. Eng. 2009, 31, 464-469.

10. Feda, J. Notes on the effect of grain crushing on the granular soil behavior. Eng. Geol. 2002, 19, 778-785.

11. Wang, B.; Jin, X.; Liu, H. Testing Study on Mechanical Properties of Slab Rockfill Dam Materials. Chin. J. Rock Mech. Eng. 2003, 22, 332-336.

12. Bagherzadeh-Khalkhali, A.; Mirghasemi, A.A. Nu-merical and experimental direct shear tests for coarse-grained soils. Particuology 2009, 7, 83-91. [CrossRef]

13. Kjaernsli, B.; Sande, A. Compressibility of some coarse-grained materials. In Proceedings of the 1st European Conference on Soil Mechanics and Foundation Engineering, Weisbaden, Germany, 15-18 October 1963; pp. 245-251.

14. Hall, E.B.; Gordon, B.B. Triaxial testing with large-scale high pressure equipment. Lab. Shear Test. Soils 1963, $361,315-328$.

15. Zhang, J. Study on Strata Movement Controlling by Raw Waste Backfilling with Fully-Mechanized Coal Winning Technology and Its Engineering Applications. China Univ. Min. Technol. 2008, 33, 183-186. 
16. Huang, Y.; Li, J.; Teng, Y.; Dong, X.; Wang, X.; Kong, G.; Song, T. Numerical simulation study on macroscopic mechanical behaviors and micro-motion characteristics of gangues under triaxial compression. Powder Technol. 2017, 320, 668-684. [CrossRef]

17. Li, M.; Zhang, J.; Zhou, N.; Huang, Y. Effect of Particle Size on the Energy Evolution of Crushed Waste Rock in Coal Mines. Rock Mech. Rock Eng. 2017, 50, 1347-1354. [CrossRef]

18. Zhang, J.; Li, M.; Liu, Z.; Zhou, N. Fractal characteristics of crushed particles of coal gangue under compaction. Powder Technol. 2017, 305, 12-18. [CrossRef]

19. Zhou, N.; Han, X.; Zhang, J.; Li, M. Compressive deformation and energy dissipation of crushed coal gangue. Powder Technol. 2016, 297, 220-228. [CrossRef]

20. Li, M.; Zhang, J.; Gao, R. Compression Characteristics of Solid Wastes as Backfill Materials. Adv. Mater. Sci. Eng. 2016, 2016, 2496194. [CrossRef]

21. He, M.; Zhou, L.; Li, J. Experimental study on water absorption characteristics of deep well mudstone. J. Rock Mech. Eng. 2008, 27, 1113-1120.

22. Huang, Y.; Li, J.; Song, T.; Kong, G.; Li, M. Analysis on filling ratio and shield supporting pressure for overburden movement control in coal mining with compacted backfilling. Energies 2017, 10, 31. [CrossRef]

23. Zhang, Q.; Zhang, J.; Zhao, X.; Liu, Z.; Huang, Y. Industrial tests of waste rock direct backfilling underground in fully mechanized coal mining face backfilling. Environ. Eng. Manag. J. 2014, 13, 1291-1297.

24. Zhang, Q.; Zhang, J.X.; Kang, T.; Sun, Q.; Li, W.K. Mining pressure monitoring and analysis in fully mechanized backfilling coal mining face-A case study in Zhai Zhen Coal Mine. J. Cent. South Univ. 2015, 22, 1965-1972. [CrossRef]

25. Fu, Z.; Feng, J. Concrete Faced Rock Fill Dam; Huazhong University of Science and Technology Press: Wuhan, China, 1993.

26. Hardin, C.S. Crushing of soil particles. J. Geotech. Eng. 1985, 111, 1177-1192. [CrossRef]

(C) 2018 by the authors. Licensee MDPI, Basel, Switzerland. This article is an open access article distributed under the terms and conditions of the Creative Commons Attribution (CC BY) license (http:/ / creativecommons.org/licenses/by/4.0/). 